\title{
Simulation and Analysis on the Control System of Stepping Actuators of Underwater Valve
}

\author{
Yanchun Zhang ${ }^{1,}$, , Yunpeng Wang ${ }^{2, b}$, Jiazhen Zhang ${ }^{1, c}$, \\ Weili $\mathrm{Li}^{2, \mathrm{~d}}$, Mingzhe Zhao ${ }^{1, \mathrm{e}}$ \\ ${ }^{1}$ No, 199, Fifteenth Haibin Road, Free Trade Zone of Tianjin Port, Tianjin, 300000, China \\ ${ }^{2}$ College of mechanical and electrical engineering, Harbin Engineering University, Harbin, 150001, \\ Heilongjiang, China \\ azhangyc@mail.cooec.com.cn, b1079912903@qq.com, czhangjiaz@mail.cooec.com.cn, \\ d1562019770@qq.com, èzhaomz@mail.cooec.com.cn
}

Keywords: The Stepping Actuator, Controlling System, Response Characteristics, Simulation. Abstract. The stepping actuator is a device used to control the choke opening in the subsea production. The performance of the control system is directly related to the subsea production schedule and safety. In this paper, the working principle of underwater stepping actuators is studied. Moreover, the response and steady state characteristics of the control system are simulated and checked. Then take some measures to improve its control characteristics, and make it meet the control requirements.

\section{Introduction}

It is generally known that the working environment of subsea oil-gas production system is very special. Excellent performance actuator is essential in order to the valve will be working normal. In general, to the underwater valve which will be working in the shallow water, in most cases, foreign companies adopt handwheel and gearbox and then operated by diver under the water. However, it should be operated by the ROV, or use the hydraulic control system to achieve the expected function when the valve actuator will be working in the deep-water. Most of the power source of valve actuators which will be working in the deep-water is hydraulic and the hydraulic fluid conveyed by umbilical cables [1-2]. The stepping actuator is a device used to control the choke opening in the subsea production. The reliability of the control system directly related to the subsea oil and gas production. Therefore, it is of particular importance that the design of control system when designing the underwater valve stepping actuators.

\section{The Structure of Stepping Actuators}

Stepping actuators are the typical actuator in the subsea oil production equipment, its structure is shown in Fig.1. It is mainly used to control the choke in the subsea oil production equipment. Generally, stepping actuator mainly contains shell, ratchet, connecting rod, spring and single-acting hydraulic cylinder. And there are two single-hydraulic cylinders, one is used to control the choke opening, and the other is used to control the choke closing. Every time due to the action of hydraulic oil, the single-hydraulic cylinder will drive the choke turn a circle, being along with the relevant linear displacement. The choke will be fully opened or closed when the times of the action of hydraulic oil reaches the set number [3].

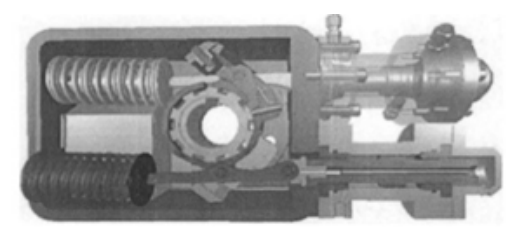

Fig. 1 Stepping actuators 


\section{The Working Principle of Stepping Actuators}

The control block diagram of closed-loop system of the production choke is shown in Fig. 2. The operator sends commands to the subsea control module through the main control station on the water, then the subsea control module will open the inner related electro-hydraulic reversing valve. Hydraulic fluid drives the main valve spool of the electro-hydraulic reversing valve make a corresponding move, which will control the single-hydraulic cylinder located inside of actuator to move. The single-hydraulic cylinder drives ratchet mechanism which is located inside stepping actuators, and then the connecting rod connected with the ratchet pushes the valve of the production choke into opening a certain extent. Repeat the above process, and the production choke will gradually open. On the contrary, if the electro-hydraulic reversing valve, which controls the production choke to close, is opened, the ratchet mechanism driven by the hydraulic fluid will be controlled to turn into the opposite direction. So the production choke will close a certain extent. Repeat the above steps, ensuring the number of times of closing steps and the opening steps in of the production choke is equaled, the extent of closure is the same. The production choke will be fully closed when the number of times of repeat steps equals the set number.

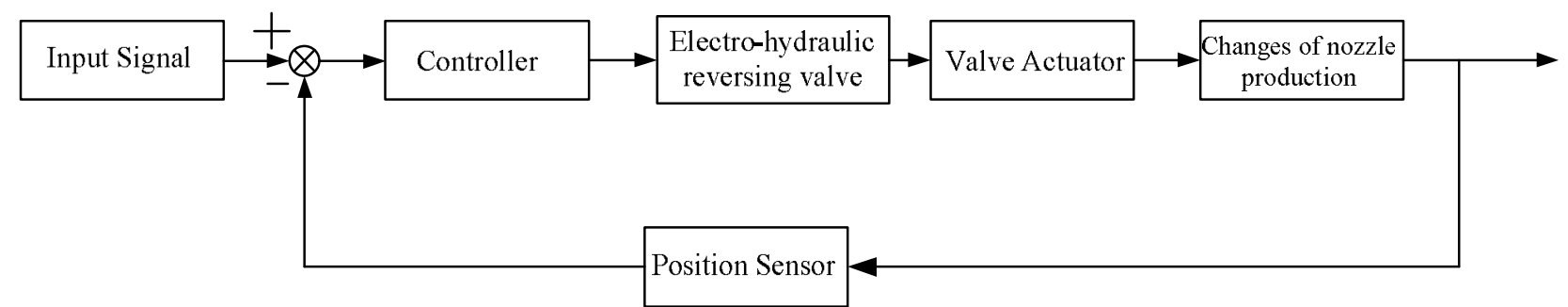

Fig. 2 The closed-loop control block diagram of the production choke

In order to achieve more precise control, position sensor should be installed in the moving parts of the production choke to detect its changes in the degree of opening. The subsea control module receives data that feedback from position sensor, and then send the data to the main control station on the water. So operators can make the right responses according to the feedback information [4-5].

\section{Control System Modeling}

Stepping Actuators. The stepping actuator contains ratchet mechanism, two single-acting hydraulic cylinders and some subsidiary parts. The number of teeth of the ratchet $Z=10$. So the turning angle of ratchet is $\theta$ when the distance of the single- acting hydraulic cylinder runs once is $\mathrm{L}$, then

$$
\theta=\frac{360^{\circ}}{10}=36^{\circ} \text {. }
$$

When the turning angle of stepping actuators ratchet is $\theta_{p}$ and setting the motion stroke of the singleacting hydraulic cylinder is $x_{p}$, there will be

$$
x_{p}=\frac{\theta_{p}}{36} \times L \text {. }
$$

Electro-hydraulic Reversing Valve. The schematic diagram of the electro-hydraulic reversing valve is shown in Fig. 3. It is shown in Fig. 3 that the main valve of the electro-hydraulic reversing valve is four-sided valve with Zero opening. Due to the rapid development of mechanical processing technology in recent years, the working accuracy of mechanical parts has increased dramatically during the past couple of decades. So the slide valve of actual processing is quite close to the slide valve designed based on the standard of theory. The slide valve is designed as sharp edges to throttle 
with ignoring radial clearance between valve core and pocket [6], in research.

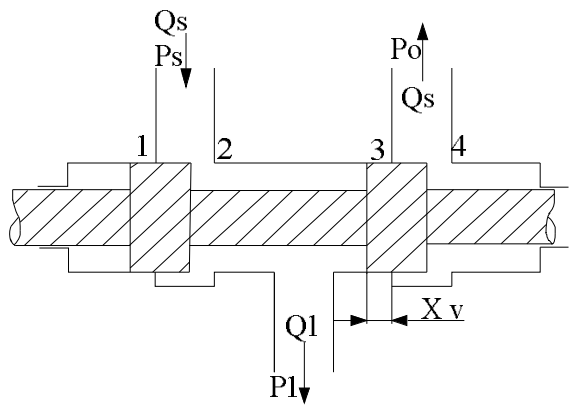

Fig. 3 Four-sided valve with Zero opening

Suppose that the displacement of the slide valve core is $x_{v}$, the left direction is positive, the flow of valve outlet is $Q_{L}$, and the pressure of valve outlet is $P_{L}$. Suppose that the derivative coefficient of $x_{v}$ is $k_{q}$, the derivative coefficient of $P_{L}$ is $k_{\mathrm{c}}$, and the each parameter of two sides' of the four-sided valve with Zero opening is identical. Then the following flow equation of four-sided slide valve will be contained by selecting rectangular openings as the restriction of steering system of four-sided slide valve.

$$
Q_{L}=k_{q} x_{v}-k_{c} P_{L}
$$

Hydraulic Cylinder with Single Action. The stressful and movement model of hydraulic cylinder with single action is shown in Fig. 4.

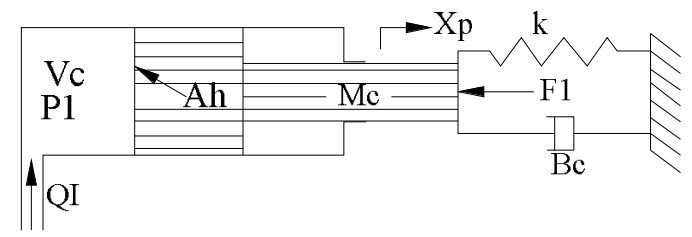

Fig. 4 Hydraulic cylinder with single action

Suppose that the flow of oil inlet chamber is $Q_{L}$, the coefficient of leakage is $C_{i p}$, the volume of oil inlet chamber is $V_{c}$ and its initial volume is $V_{0}$, the piston area is $A_{h}$. The piston displacement of hydraulic cylinder is very small, that is to say $\left|A_{h} \times x_{p}\right| \ll V_{0}$. So it is known that $V_{c} \approx V_{0}$. Calculating the Laplace transform to incremental of the continuity equation of hydraulic cylinder with single action, there will be

$$
Q_{L}=A_{h} \times S \times x_{p}+C_{i p} \times p_{l}+\frac{V_{0}}{\beta_{e}} \times S \times p_{l}
$$

The total mass of piston and load is $M_{c}$, and their viscous damping coefficient is $B_{c}$. The rigidity of spring is $K$, the additional load is $F_{l}$. Then calculating the Laplace transform to incremental of the force balance equation [7] of hydraulic cylinder with single action, there will be

$$
p_{l} \times A_{h}=M_{c} \times S^{2} \times x_{p}+B_{c} \times S \times x_{p}+k \times x_{p}+F_{l} .
$$

Supposing that the pressure coefficient of total flow is $k_{c e}$, the coefficient of entrance flow is $k_{q}$, the corner frequency of inertia link is $\omega_{r}$, and the natural frequency is $\omega_{0}$. The variable $Q_{L}$ and $p_{l}$ can be eliminated by combing Eq. (3), Eq. (4), and Eq. (5). Then the responding equation that the output 
displacement of hydraulic cylinder with single action to the displacement of four-sided valve with Zero opening can be calculated as follows:

$$
\frac{x_{p}}{x_{v}}=\frac{\frac{A_{h} \times k_{q}}{k_{c e} \times k}}{\left(\frac{S}{\omega_{r}}+1\right) \times\left(\frac{S^{2}}{\omega_{0}}+\frac{2 \times \xi_{0}}{\omega_{0}} \times S+1\right)} .
$$

It is known that the spring's rigidity of stepping actuators $k=380 \mathrm{~N} / \mathrm{mm}$, the motion stroke of hydraulic cylinder $L=410 \mathrm{~mm}$, the diameter of piston $D_{h}=92 \mathrm{~mm}$ and the diameter of piston rod $D_{r}=50 \mathrm{~mm}$, the total mass of spring and additional load $M_{c}=100 \mathrm{~kg}$, the elastic modulus of hydraulic oil $\beta_{e}=600 \mathrm{MPa}$ and its damping $B_{c}=0.15 \mathrm{~N} / \mathrm{s}$, the total flow's pressure coefficient $k_{c e}=5.2 \times 10^{-10} \mathrm{~m}^{3} /(\mathrm{Pa} \times \mathrm{s}), k_{q}=0.76 \mathrm{~m}^{2} / \mathrm{s}$. Taking the above data into Eq. (5) and Eq. (6), and simplifying the equation can obtain that

$$
\frac{x_{p}}{x_{v}}=\frac{25.38}{(22.2 S+1) \times\left(0.14 S^{2}+0.03 S+1\right)} \text {. }
$$

\section{The Simulation Analysis of the Control System}

Using the Simulink blocks included in the MATLAB to simulate the transfer function of the stepping actuators, and then to verify the stability of system according to the simulation curve.

According to the Eq. (7), establishing the control block diagram in the Simulink blocks and making the control system work, can we get the simulation result that is shown in Fig. 5. Fig. 5 illustrates that the damping of the system is relatively small when directly simulating the closed-loop control system of the production choke which controlled by the stepping actuator. The step response curve is unstable, so gradual divergence will happen since $80 \mathrm{~s}$.

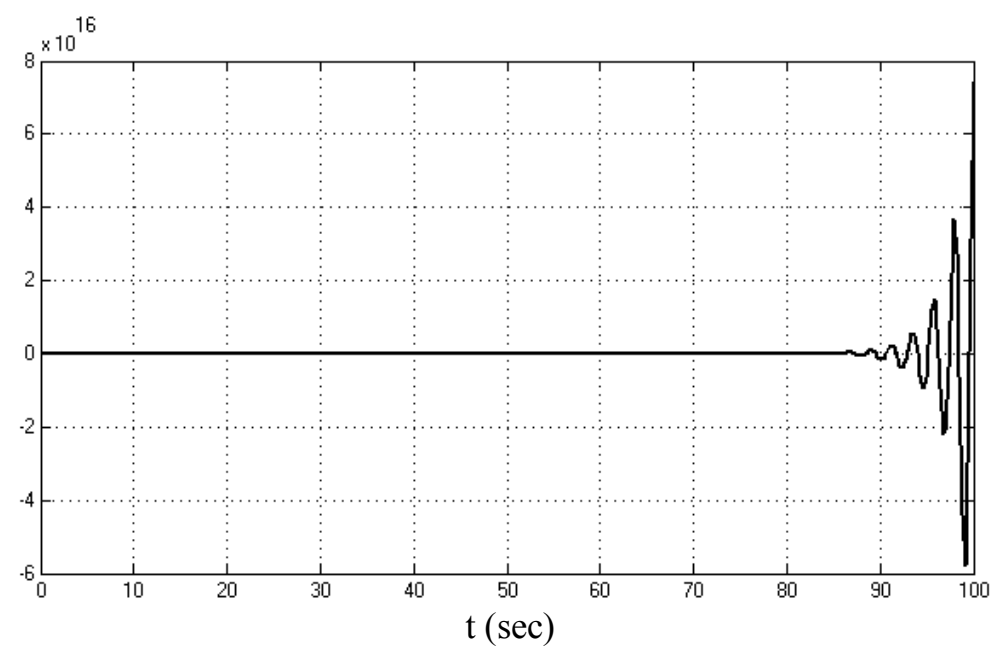

Fig.5 The step response curve of the control system

In order to improve the response of the system and make it convergence and stability, the structure of the system should be adjusted and added appropriate correction device. In this study, it chose to add the zeros and poles to transfer function, which is meaning adding a controller. Adjust the Bode diagram of the control system in the MATLAB software, so the gain margin (GM) and phase margin (PM) is positive [8] at the same time, which can determine the system is stable. By adjusting, the controller function can be calculated by the MATLAB as follows: 
Add the controller of Eq. (8) to the control block diagram of the system, as shown in Fig. 6.

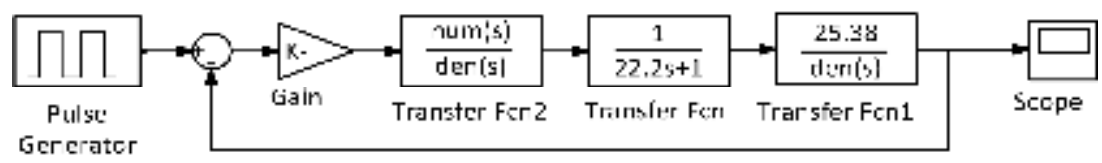

Fig. 6 The control block diagram of the improved system

Operating the improved control system, the simulation result is shown in Fig. 7. Fig.7 shows that the step response curve of the improved control system is stable, the adjustment time is about $0.2 \mathrm{~s}$, the overshoot of response is $10 \%$ and there is no steady-state error. By studying, we can know that the improved system meets the control requirements.

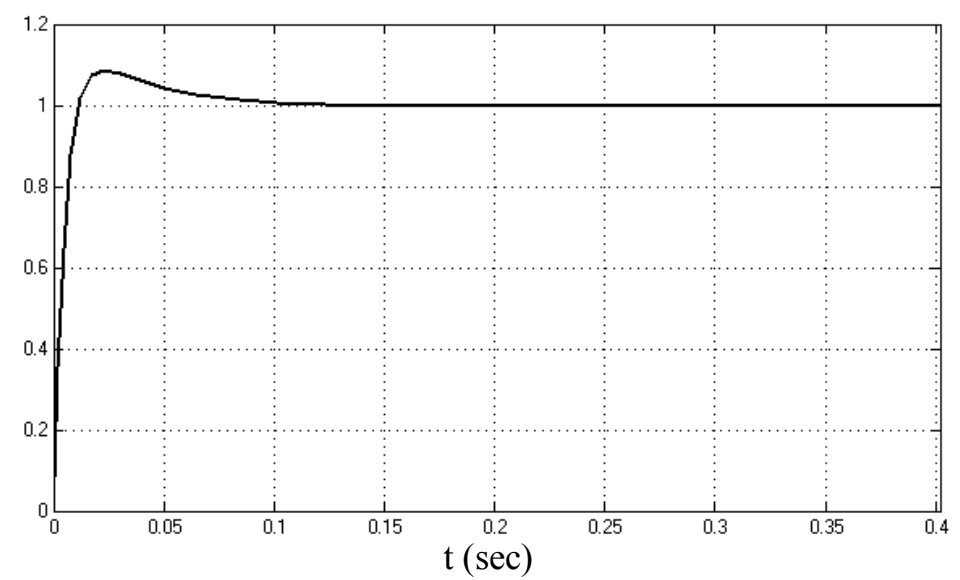

Fig. 7 The step response of the improved control system

\section{Conclusions}

In our country's energy exploration in the future, it is the key point about exploring petroleum and natural gas. However, the development and research of the production equipment of the subsea oil and gas is still in its infancy in our country. The valve actuator is an important device used in the subsea production system. Its working performance is directly related to the subsea production safety. In this paper, the working principle of subsea valve stepping actuators is studied. Moreover, the response characteristics of the control system is simulated and checked by MATLAB software. Then take some measures to improve its response characteristic, and make it meet the control requirements of system, which has certain meaningful value in the development of deep-water oil and gas field.

\section{Acknowledgement}

This work was financially supported by the National Science and Technology Major Project (2011zx05027-004).

\section{References}

[1] Yue ZHONG. Study on selection of the valve actuator[J]. Technology Innovation and Application. 2013(18). (In Chinese)

[2] Min WANG, Lihua XI. Idle running compensation of actuators[J]. A technology. 2005(03). (In Chinese)

[3] GB/T21412.6-2009/ISO13628-6:2000, Petroleum and natural gas industries-Design and operation of subsea production systems-Part 6: Subsea Production control systems[S], 2007:16. (In Chinese) 
[4] The editorial board for "Design Guidelines for Offshore Oil Engineering". Offshore oil engineering exploitation technology of deep water oil and gas fields[M]. Beijing: Petroleum industry press, 2011: 172. (In Chinese)

[5] The editorial board for "Deepwater Engineering Handbook". Deepwater Engineering Handbook[M]. China National Offshore Oil Corporation. 2010: 380. (In Chinese)

[6] Lei Li, Ping Deng, Fenggong Zhang, et al. Research on the Application of Electro-hydraulic Directional Control Valve in Underwater Production Control System[A]. China Petroleum Machinery. 2013.41(3):60. (In Chinese)

[7] Jingtai Guan. Electro-Hydraulic Control Technology[M]. Shanghai: TONGJI UNIVERSITY PRESS, 2003: 65-83. (In Chinese)

[8] Baiwei Guo, Zaozhen Liu, Yongshan Liu. Control system analysis and design[M]. Beijing: Publishing House of Electronics Industry, 2014: 45-69. (In Chinese) 